\title{
A Century of Meteorology.*
}

By Sir Napter Shaw, F.R.S.

$\mathrm{T}$ $\mathrm{HE}$ progress of the science of meteorology to the evolution of the weather-map and beyond that to the introduction of broadcasting, which makes its treatment a matter of universal interest, can be traced from the unco-ordinated efforts of private observers, which were criticised in a report to the British Association in 1832 by J. D. Forbes, professor of natural philosophy in the University of Edinburgh, as the feeble expression of an infant science. It passes through the unfulfilled ambition of a Meteorological Society of London expressed in its transactions published in 1839 by John Ruskin, who defended the science as of universal interest and as necessarily dependent on universal co-operation, and then through the co-operative investigation of weather at sea, by which the tropical hurricane earned the name of 'cyclone' from Henry Piddington and riveted the idea of a travelling vortex on the science.

Co-operation in the study of weather at sea found further expression in the International Conference at Brussels in 1853, suggested by Lieut. M. F. Maury of the U.S. Navy, and the consequent formation of the Meteorological Department of the Board of Trade under Admiral FitzRoy in $\mathbf{1 8 5 4 .}$

About the same time, co-operation was extended to the collection of simultaneous observations from different stations by the aid of the electric telegraph. It began with some spasmodic efforts in 1851 , and gradually developed until the weather-map in its present form, with the aid of wireless, is the most striking example of successful international co-operation.

Within each twenty-four hours the British Meteorological Office collects some seven thousand facts about the weather based on simultaneous observations at some hundred stations in Europe, Africa, Asia, the eastern Atlantic, its ships and its islands, in Greenland, Iceland and Spitsbergen, and the islands of the far north. The observations at the surface are supplemented by incidental observations of clouds and winds in the upper air, and occasional observations of pressure and temperature there too. Four hours of observation are chosen, and between the observing hours of $7 \mathrm{~h}$. and $13 \mathrm{~h}$. the observations for the twenty-four hours are transcribed, charted, printed, and posted with the inferences drawn from them about the weather to come.

For land-stations co-operation took the form of compiling observations of the meteorological elements as an expression of climate under the guidance of the British Meteorological Society from 1850, the Scottish Society from 1856, and the British Rainfall Organization from 1858. From the very beginning of regular observations the chronological sequence was used to identify the rhythm of the sequence of weather at individual stations as diurnal and seasonal. The temptation to seek for evidence of other rhythmic periods,

* Substance cf a paper entitled "Meteorology after the Century" (Mathematical and Physical Sciences) of the British Association on Sept. 25 during the centenary meeting in London. especially those of the moon, was irresistible. It was ultimately guided into the righteous paths of harmonic analysis and the periodogram, which form an interesting chapter in the scientific history of the century.

Correlation came later when Galton had become disappointed with the behaviour of the cyclone and anticyclone. Francis Galton, who was one of the general secretaries of the British Association, had a great share in the development of the science of meteorology. He was actively interested in the establishment of a weather-map and also in the Kew Observatory in the Old Deer Park at Richmond, which was maintained by the British Association, and among other things he developed methods of recording automatically the variation of the meteorological elements.

When FitzRoy used his weather-maps to make public forecasts of weather and issue storm-warnings some prominent scientific authorities thought it premature, and on FitzRoy's death, at the request of the Government, a Meteorological Committee was appointed by the Royal Society to take on the work of the Meteorological Department of the Board of Trade and bring it into co-operation with the meteorological work of the British Association's Observatory at Richmond.

During twelve years a strenuous effort was made, chiefly under Galton's guidance, to use the records of the instruments at seven observatories like Kew to interpret the sequence of weather shown on the daily maps. Meanwhile forecasts were suspended. For twelve years every curve drawn by the instruments was reproduced with the associated maps for public information. The systems of closed isobars, now known as the cyclonic depression and the anticyclone, were the most striking features of the sealevel maps. The track and behaviour of every one of them during the twelve years was "set in a notebook learned and conned by rote". They were enthroned as Nature's proctors for the guidance of weather, and under their guidance forecasting was restored in 1879 by direction of those who had been critical in 1865 .

The method of forecasting on the basis of cyclones and anticyclones was set out effectively by the Hon. Ralph Abercromby. The problem of the sequence of weather seemed to be solved. It was supposed that the progress of storms across the Atlantic could certainly be anticipated. Further investigation of the upper air by shell-bursts, by balloons, by the study of clouds under a new directing council, would clear up all the outstanding difficulties.

Somehow the effort failed. The maps used were bounded on the west by the Irish coast. Cyclones and anticyclones suggested rules of behaviour but did not keep to them, and a magnificent effort was made to find out the how and why of the irregularities by maps of the Atlantic and adjacent continents for the days of the year of 
polar exploration 1882-83; but no one has ever been able to make out a rational account of the behaviour of cyclonic depressions. The Norwegian school has traced with marked success the influence of the movement of the different kinds of air of which they are composed, but the origin of the currents of which they are composed is not yet understood. Disappointed, the council turned its attention to harmonic analysis of hourly values as a method of discovering the latent causes of weather, and Galton transferred his interest to eugenics.

All this while, Buys Ballot's law that wind is along the isobars with a deviation towards the low pressure and dependent for its strength upon the closeness of the isobars was recognised, and when the phenomena of turbulent motion were explained, it became apparent that the surface-layer was so much affected by turbulence that regularity in the relation of pressure to the surface-wind was not to be expected. But observation showed that in the upper air it might be assumed that the effect of turbulence is negligible, and the geostrophic relation between pressure-gradient and horizontal wind under the influence of the earth's rotation might be regarded as a definite meteorological law, most definite where isobars are straight and parallel. Moreover, it accounts for the development of high pressure, a matter which has been neglected in the study of weather. Wherever the horizontal wind in an air-current is not in agreement with the formula the rotation of the earth will push it sideways, from high to low if the horizontal component is too slow, from low to high if it is too fast. The adjustment will always be operative over the whole mass of the moving air so that the air may be regarded as adjusting the gradient to its motion as a bicyclist adjusts his inclination to the vertical.

In the concentration of attention on the closed isobars of cyclones and anticyclones the study of the straight isobars between them has been overlooked; and it may fairly be asserted that if the origin of the currents with straight isobars can be traced, they may be relied upon to adjust the pressure-gradient to meet the exigencies of the wind in the upper air, which is an indubitable expression of actual energy of vast amount.

Meanwhile, the air is everywhere stratified according to its entropy, and any change in the entropy by gain or loss of heat, by conduction to or from the ground, by radiation to or from the air, or by the condensation or evaporation of water within its mass, will have its effect on the stratification, and the readjustment of the stratification will transform the thermal energy of the air into the actual energy of wind. The currents of straight isobars have, therefore, an obvious claim upon the students of the dynamics of the atmosphere. The extension of the area of the daily map to include the whole hemisphere makes productive investigation possible.

To summarise, our survey leads to the conclusion that meteorology has been mistaken in regarding the cyclonic depression and the anticyclone of a hypothetical sea-level map as the principal agents in control of the energy of weather, and asks for the consideration of the currents in the free air indicated by straight isobars as expressing the real estate of energy in the atmosphere, while the differences in the distribution of entropy and water-vapour associated therewith represent its potential estate.

\section{Recent Developments in Optical Glass Manufacture.*}

\section{By W. M. Hampton and W. N. Wheat.}

$\mathrm{T}^{\mathrm{H}}$ HE demand for particular types of optical glass has changed considerably during the postWar period, largely under the influence of the remarkable development of the modern photographic lens, which has been based on the production of the more extreme types of glass, notably the barium crowns.

This change is shown by the following table of the percentage of the various broad types manufactured by Messrs. Chance Brothers and Co., Ltd., of Birmingham, in the years 1914, 1918, 1929.

\begin{tabular}{|c|c|c|c|}
\hline & 1914. & 1918. & 1929. \\
\hline Hard Crown and Zine Crown & 24 & 29 & 7 \\
\hline Borosilicate Crown & 23 & 14 & 18 \\
\hline Light Flint and Baryta Light & & & \\
\hline Flint & 27 & 14 & 11 \\
\hline Dense Flint $\therefore$ & 23 & 27 & 13 \\
\hline Extra Dense Flint . & 2 & 4 & 16 \\
\hline Barium Crowns & 1 & 12 & 35 \\
\hline
\end{tabular}

Recent research has enabled the manufacture of the barium glasses to be put on a routine basis, the

* Substance of a paper read at the Science Museum, Sonth Kensington, on Oct. 29, in connexion with the Exhibition of Modern Technical and Artistic Glasses. variation in optical constants from one melt to another not being appreciably greater than is normally obtained with the simpler types. This is largely due to the utilisation of refractories for the melting-pots of a composition which is sufficiently resistant to the solvent action of these very corrosive glasses, thus minimising the trouble, once serious, of dilution by aluminous material dissolved from the pot wall. Improvements in the knowledge of melting technique and of the volatilisation losses which accompany the process of fusion have enabled a more strict control to be exercised over the types of barium glasses which contain a percentage of boric oxide in place of silica, these glasses being indispensable in the manufacture of the modern wide aperture photographic lens. The most extreme example in this series has a refractive index of 1.6140 and a value of $V$, or reciprocal dispersive power of $59 \cdot 8$, representing the practical limit to which it has so far been found possible to go.

A knowledge of volatilisation losses is of great importance if exact control of the melting of the flint glasses is to be maintained, and it has been established that, within the limits of composition

No. 3240 , VoL. 128] 